\title{
Some experience and preliminary conclusions from the experimental monitoring of the temperature regime of a subgrade structure
}

\author{
L. Ižvolt ${ }^{1}$, P. Dobeš ${ }^{1} \&$ M. Pitoňák ${ }^{2}$ \\ ${ }^{I}$ Department of Railway Engineering and Track Management, \\ Faculty of Civil Engineering, University of Žilina, Slovak Republic \\ ${ }^{2}$ Centre of Excellence in Transport Engineering, \\ Faculty of Civil Engineering, University of Žilina, Slovak Republic
}

\begin{abstract}
In addition to other topics on railway engineering, the Department of Railway Engineering and Track Management is permanently paying attention to the issue of the non-traffic load of railway track (track load of climatic impacts) for the purpose of verification and possible adjustments of the existing methodology of the railway subgrade structure design to the adverse effects of frost used on the Slovak railways. For this purpose, the model of a railway track structure was built - Experimental Stand DRETM I - with an inbuilt thermometer in its individual structural layers and their interfaces, connected to recording equipment. This paper presents the characterized results of individual winter periods observed since 2003, its partial analysis is made and it states some fundamental knowledge necessary to be taken into account in the design and assessment of the railway track structure to the adverse effects of frost. Based on the evaluation of experimental measurements and knowledge obtained so far, a draft design nomogram for the design of the structure of a railway track on a non-traffic load was made, which greatly simplifies this whole process of design and assessment, compared with the current methodology in TNŽ 736312 "The design of structural layers of subgrade structure".
\end{abstract}

Keywords: railway track, design, temperature regime, frost depth, frost index. 


\section{Introduction}

There have often been proclaimed changes in climatic conditions in recent years which could and should have, apart from other things, their impact on the construction of railway track - structural composition and thickness of the individual structural layers of subgrade structure. Climatologists predict that there are already, but also in the future, will be achieved lower intensity values of frost and amounts of snowfalls, as it was in times when meteorological stations in Europe started monitoring these values. This should logically be also reflected in the current and future designs of structural thicknesses of subgrade structure. However, while taking into account these assumptions results mostly in the design of a smaller structural thickness of protective (frost-resistant) layer of subgrade structure, on the contrary, simultaneously increasing requirements on quality of track in the connection of modernization of the railway network of the Slovak Republic (hereinafter referred to as "ŽSR") and increasing axle loads and track speed, all of which always leads to a design of greater structural thickness of the base (bearing) layer of the construction of subgrade structure.

The construction of subgrade structure in the Slovak Republic is designed using TNŽ 736312 [1]. There is a section in this legislative document dealing with the design of the construction of subgrade structure to the adverse effects of frost resulting from research, realized even in the $70^{\text {th }}$ of the last century. Therefore, it is more desirable, not only in response to the proclaimed changes in climatic conditions in Europe, but also in connection with new building materials, which have been applied to the construction of subgrade structure in recent years, to verify not only the current methodology of subgrade structure design to the adverse effects of frost, but also coefficients of thermal conductivity of materials that are currently standard in the construction of subgrade structure and also affect its temperature regime.

Further to the above, there are presented and briefly analyzed the results of multi-annual experimental monitoring of temperature regime of subgrade structure in experimental model of railway track (Experimental Stand) of the Department of Railway Engineering and Track Management (hereinafter referred to as "DRETM") and stated design nomogram for the design of subgrade structure to the adverse effects of frost in this paper.

\section{Climatic conditions and temperature regime of subgrade structure}

Climatic conditions have a significant role in the examination of the causes and consequences of railway substructure failures. These are necessary to quantify with such characteristics they can express their impact on the temperature regime of subgrade structure and the depth of freezing in its structure as well. One of the most important characteristics of a particular climatic region is the air temperature which varies during the day (higher temperatures during the day, lower during the night), but mainly during the year (higher temperatures in summer, lower in winter). The course of air temperatures is expressed using the following characteristics [2]: 
a) average daily air temperature $\theta_{s}\left({ }^{\circ} \mathrm{C}\right)$

$$
\theta_{S}=\frac{\theta_{7}+\theta_{14}+2 . \theta_{21}}{4}
$$

where $\theta_{7}, \theta_{14}$ and $\theta_{21}$ represent air temperatures measured at 7 (7 am), 14 (2 pm) and $21(9 \mathrm{pm})$ o'clock of Greenwich Mean Time $2 \mathrm{~m}$ above ground,

b) the maximum air temperature $\theta_{\max }$ and the minimum air temperature $\theta_{\min }$ in daily, or year cycle,

c) an average annual air temperature $\theta_{m}$ expressed as follows:

$$
\theta_{m}=\frac{\sum_{i=1}^{365} \theta_{s}}{365}
$$

d) frost index $I_{F}\left({ }^{\circ} \mathrm{C}\right.$ a day) - maximum negative value of sequential sum of average daily air temperatures in winter.

From the listed characteristics, frost index $I_{F}$ is the most common characteristic that is used to express temperature regime and assessment of the construction of subgrade structure in terms of its protection against frost. Frost index is not constant value, but considerably variable. It directly depends on the air temperature, which is influenced by several factors. The impact of individual factors on the size of frost index is only possible to express mathematically to a certain extent. The most accurate determination of frost index is possible only by direct measurement of temperature. Temperature regime of subgrade structure is defined as a course of changes in the temperature state of the individual layers of the construction and soil in the structure, which are caused by sunlight, heat radiation and air temperature changes during the day, or year. The important characteristic of this effect and also in terms of the design of subgrade structure to the adverse effects of frost is the frost depth of subgrade structure $D_{F}$, which is followed from the equation according to a legislative document [1]:

$$
D_{F}=0.045 \cdot \sqrt{I_{F}}
$$

Considering the term frost depth of the construction of subgrade structure we understand the distance of zero isotherm $\left(0^{\circ} \mathrm{C}\right)$ from the surface of track ballast. There are following factors which generally affect freezing depth of subgrade structure:

a) course of temperatures in winter frequently characterized by frost index $I_{F}$,

b) thermo-resistant properties of structural layers of subgrade structure,

c) state of soil subgrade (granulometric composition, humidity $w$, volume weight $\rho$ and etc.),

d) thickness of snow cover on the surface of railway track body. 
Frost index $I_{F}$ is determined by summing the mean daily air temperatures $\theta_{S}$ in winter, according to the equation:

$$
I_{F}=\sum_{t_{b}}^{t_{f}} \theta_{s}
$$

which gives a mass curve in ${ }^{\circ} \mathrm{C} /$ day. If we use the value of temperature on the surface of the track structure (surface of track railway ballast) instead of $\theta_{S}$, we receive frost index on the surface $I_{F s}$.

\section{Characteristics of experimental monitoring of temperature regime and frost depth of subgrade structure}

One of relatively reliable, but time and labour most demanding methods is monitoring of frost depth of subgrade structure $D_{F}$ using direct experimental measurement. There was built a experimental model of railway track for this purpose in 2003, labelled as Experimental Stand DRETM I - fig. 1, in the former premises of the Faculty of Civil Engineering, which is used to monitor the temperature regime of subgrade structure and its most important characteristics - frost depth of subgrade structure based on the monitoring of the position of zero isotherm. This is determined from the continuous temperature measurement in the construction of subgrade structure using inbuilt resistance thermometers. Temperatures in individual components (layers) of subgrade structures of experimental stand and air temperatures $(2 \mathrm{~m}$ above the surface of surrounding terrain and on the surface of track ballast) are continuously monitored during the experimental measurement, under which the following parameters are determined:

- frost index of air $I_{F}$ and on the surface of ballast bed (BB) $I_{F s}$,

- frost depth of subgrade structure $D_{F}$,

- the minimum temperatures $\theta_{\min }$ and the maximum temperatures $\theta_{\max }$ in subgrade structure,

- the mean daily $\theta_{S}$ and an average annual air temperature $\theta_{m}$.

In order to apply the measured parameters for the constructions of the railway substructure body, or subgrade structure constructed from other building materials, or for the constructions of railway track of other shapes (side-hill cut, embankment, cut), mathematical modelling of temperature regime of subgrade structure is made in parallel using Canadian software SVHEAT SoilVision. The results of these simulations and their comparison with temperature regimes actually measured in Experimental Stand DRETM I in the period 2003-2013, which are characterized in this part of the article, are listed in the following contribution of authors Ižvolt and Hodas: Modelling of temperature regime of railway track structures and its comparison with the results of experimental measurements, which is also published in this collection. 


\subsection{Structural sections of Experimental Stand DRETM I}

The construction of the Experimental Stand DRETM I consists of 1:1 scale model of the section of railway track kept in the ground level. The railway superstructure consists of track skeleton formed by $60 \mathrm{E} 1$ rails fastened by means of Vossloh Skl 12 spring clips, SB 8 sleepers and track ballast fr. 31.5/63 $\mathrm{mm}$ of total thickness $500 \mathrm{~mm}$. Railway substructure forms subgrade structure of type 3 with inbuilt geo-composite Macrit GTV/50, where the base layer consists of a $450 \mathrm{~mm}$ thick layer of crushed aggregate fraction $0 / 32 \mathrm{~mm}$, which is stored on saddling subgrade of sandy clay. The thickness of the base layer was designed according to Regulation TNŽ 736312 [1], where the value $I_{F}=480^{\circ} \mathrm{C}$.day was used as the design value of frost index for Žilina. There are 11 resistance thermometers Pt 100 used to monitor the temperature in different structural layers of experimental model of track, where 1 thermometer is located on the surface of the track ballast (in the axis of the stand) and other 10 thermometers are located in two vertical rows at distance of $150 \mathrm{~mm}$ ( 2 thermometers on the surface of the base layer, 4 in the base layer, and 2 below the surface). Individual thermometers are connected to the registration control panel REGMET MS 4, which is set to recording interval of 30 minutes. Air temperature, measured $2 \mathrm{~m}$ above the surface of surrounding terrain, is an important input data within the evaluation of measurement, where an external air temperature sensor is used for this purpose. View on the construction of Experimental Stand DRETM I and its cross-section is shown in fig. 1.

Whereas it is assumed that the snow operates as a heat insulator within the measured temperature, in order to monitor its impact, snow cover is completely removed in some periods of winter, or on the contrary, there is left a layer of the thickness approximately $100 \mathrm{~mm}$ to simulate actual operating conditions occurring on the railway track (height adjustment is carried out from the top of the rail belt thanks to the special template simulating the lower part of the railway vehicle outline).

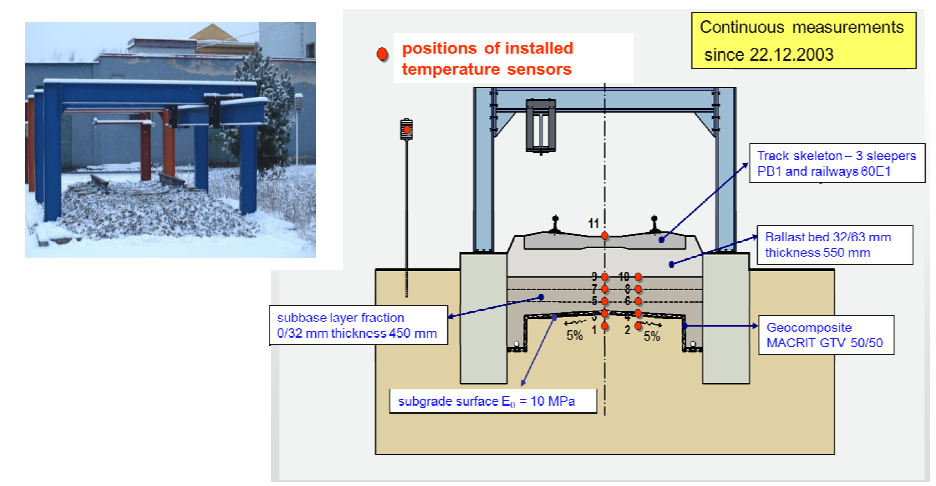

Figure 1: View on the construction of Experimental Stand DRETM I and its cross-section [3]. 


\subsection{Analysis of the results obtained from the experimental monitoring of temperature regime}

Experimental monitoring of temperature regime of the construction of railway track model (subgrade structure) has been in progress since winter 2003/2004, there has been captured a total of 10 winter periods since then till now, which vary from each other not only in the results of frost index, number of frost periods and periods of thaw, but also a variety of ratios from the perspective of the occurrence of snow cover on the construction of railway track model. The results of long-term experimental measurement obtained by the already mentioned characteristics are clearly arranged into table 1.

Table 1: Parameter values for each winter period [3].

\begin{tabular}{|c|c|c|c|c|c|c|}
\hline Winter & $\begin{array}{c}\theta_{s, \max } \\
\left({ }^{\circ} \mathrm{C}\right)\end{array}$ & $\begin{array}{c}\theta_{s, \min } \\
\left({ }^{\circ} \mathrm{C}\right)\end{array}$ & $\begin{array}{c}\boldsymbol{I}_{\boldsymbol{F}} \\
\left({ }^{\circ} \mathrm{C} \text {.day }\right)\end{array}$ & $\begin{array}{c}\boldsymbol{I}_{\boldsymbol{F} \boldsymbol{s}} \\
\left({ }^{\mathrm{o}} \mathrm{C} \text {.day) }\right.\end{array}$ & $\begin{array}{l}\boldsymbol{D}_{\boldsymbol{F}} \\
(\mathrm{m})\end{array}$ & $\begin{array}{c}I_{F} \quad \text { for } \\
D_{F, \max } \\
\left({ }^{\circ} \mathrm{C} . \text { day }\right)\end{array}$ \\
\hline $2003 / 2004^{*}$ & 13.19 & -12.31 & 168 & 58 & 0.46 & 29 \\
\hline $2004 / 2005$ & 7.97 & -13.37 & 228 & 143 & 0.70 & 165 \\
\hline $2005 / 2006^{*}$ & 5.71 & -16.68 & 388 & 248 & 0.82 & 334 \\
\hline $2006 / 2007$ & 13.02 & -5.26 & 16 & 14 & 0.33 & 9 \\
\hline $2007 / 2008$ & 8.55 & -8.15 & 96 & 91 & 0.48 & 20 \\
\hline $2008 / 2009$ & 11.13 & -11.78 & 150 & 130 & 0.58 & 145 \\
\hline $2009 / 2010$ & 10.40 & -13.27 & 204 & 149 & 0.60 & 145 \\
\hline $2010 / 2011$ & 5.67 & -12.27 & 215 & 145 & 0.61 & 215 \\
\hline $2011 / 2012$ & 4.93 & -15.20 & 238 & 207 & 0.98 & 184 \\
\hline $2012 / 2013^{*}$ & 10.68 & -11.45 & 162 & 54 & 0.44 & 107 \\
\hline
\end{tabular}

* Parameter values obtained when snow cover thickness of approx. $100 \mathrm{~mm}$.

The winter period, here these characteristics were established for, is bounded by the first and the last frost period $\left(\theta_{s} \leq-0.1^{\circ} \mathrm{C}\right)$, while the frost period must last at least 4 days. As it can be seen from table 1, the coldest winter for the reporting period 2003 to 2013 can be considered the winter period $2005 / 2006$, when the frost index reached the value $-388^{\circ} \mathrm{C}$.day (about $81 \%$ of the design value of frost index for the area of Žilina), but the frost depth of model construction of railway track (subgrade structure - SS) did not reach maximum value for the period monitored in this winter and was "only" $0.82 \mathrm{~m}$, zero isotherm did not reach the level of subgrade (fig. 2 and fig. 3).

In terms of frozen construction of subgrade structure, the winter 2011/2012 (fig. 4 and fig. 5) is considered the most unfavourable when frost depth of model construction of the railway track (SS) reached the value $0.98 \mathrm{~m}$ while reaching frost index only $-238^{\circ} \mathrm{C}$.day (about $50 \%$ of the design value of freezing index for the area of Žilina), where, as in single winter yet, zero isotherm in the construction of Experimental Stand DRETM I penetrated below the level of subgrade located $0.95 \mathrm{~m}$ below the surface of track ballast. 


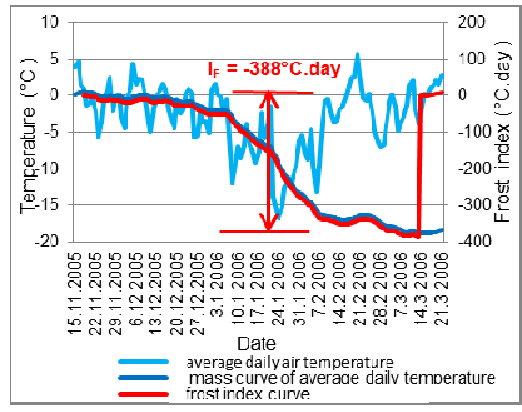

Figure 2: Frost index value for winter 2005/2006.

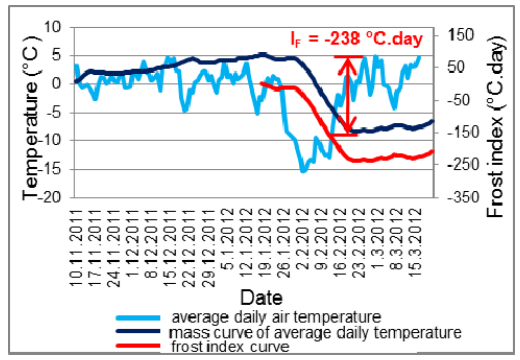

Figure 4: Frost index value for winter 2011/2012.

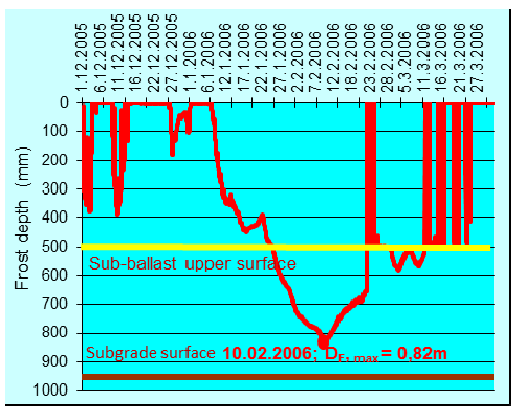

Figure 3: Frost depth value SS for winter 2005/2006.

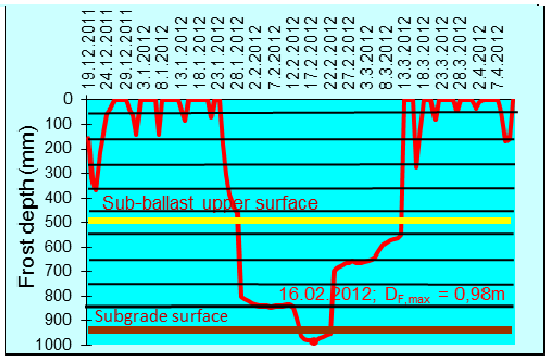

Figure 5: Frost depth value SS for winter 2011/2012.

Conversely, the mildest winter period, not only from the perspective of freezing subgrade structure, as well as maximum frost index of air achieved, can be considered winter 2006/2007, when frost depth of model construction of the railway track reached only $0.33 \mathrm{~m}$, the maximum frost index of air $-16^{\circ} \mathrm{C}$.day, which means that the zero isotherm did not get over the subgrade level of railway substructure (fig. 6 and fig. 7).

Considering the experimental monitoring of temperature regime at Experimental Stand DRETM I, there has been found an interesting finding that there is a significant difference between the air frost index $I_{F}$ and surface frost index $I_{F s}$, when there is a continuous snow cover on the surface of track ballast. As it is evident from a comparison of the winter period 2003/2004 and $2012 / 2013$, air frost index $I_{F}$ is up to three times higher than the value of the surface frost index $I_{F s}$, what confirms snow cover has a significant thermoinsulation effect resulting in the penetration of the zero isotherm reduces to the construction of subgrade structure of railway track. As the conduct of the winter period is nearly identical, there is shown only the winter period 2012/2013 in fig. 8 and fig. 9 . 


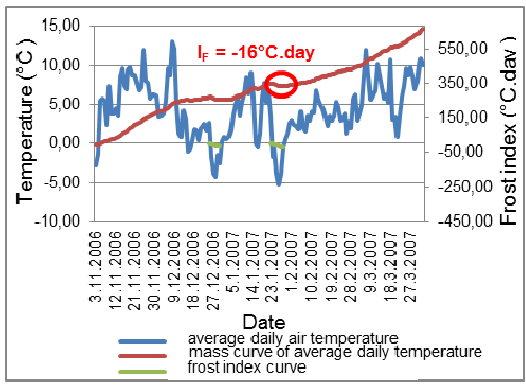

Figure 6: Frost index value for winter 2006/2007.

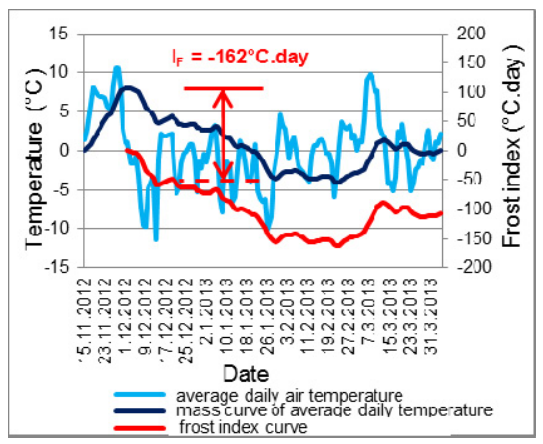

Figure 8: Frost index value for winter 2012/2013.

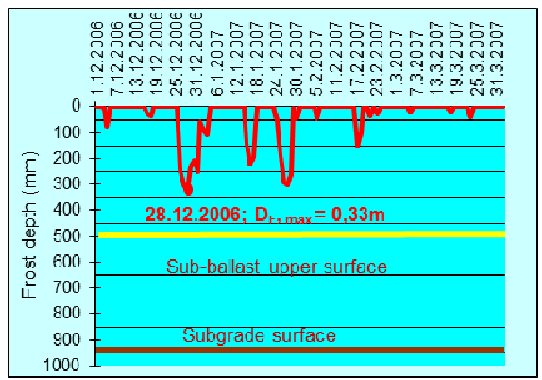

Figure 7: Frost depth value SS for winter 2006/2007.

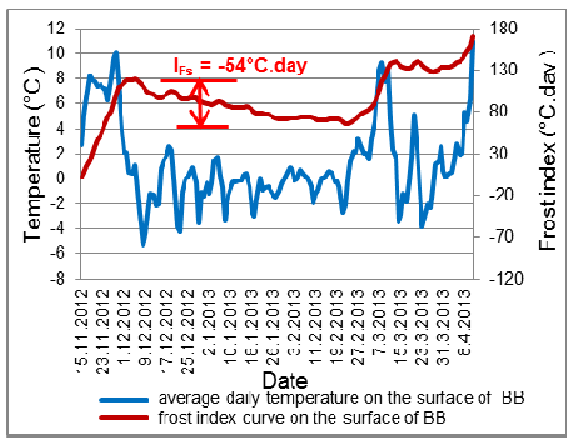

Figure 9: Frost depth value on the surface of track ballast $2012 / 2013$.

Table 1 shows that when comparing the winter period 2003/2004 with $2012 / 2013$, or the winter period 2009/2010 with 2010/2011 we can find that the differences in the frost index of air values obtained, or frost index on the surface of track ballast and frost depth of subgrade structure obtained are minimal, but the maximum frost depth in the construction of subgrade structure did not occur at approximately the same time, or during the winter period and even when reaching approximately the same frost index. Considering winter 2003/2004, maximum frost depth of the construction of subgrade structure in Experimental Stand DRETM I was reached when achieving the frost index of $29^{\circ} \mathrm{C}$.day, while in winter $2012 / 2013$ it was $107^{\circ} \mathrm{C}$.day - fig. 10 and fig. 11 .

The same phenomenon was also confirmed when comparing the winter period 2009/2010 and 2010/2011, since the maximum frost value of the construction of subgrade structure in the winter period 2009/2010 was reached when the index was only $145^{\circ} \mathrm{C}$.day, while in the winter period $2010 / 2011$ the value of frost index was $215^{\circ} \mathrm{C}$.day - fig. 12 and fig. 13 .

It is obvious that the frost index is not the only parameter influencing the frost depth, but this is also influenced by the winter period, thus the number and intensity of freezing and thaw, as well as an average annual temperature, which 
affects the amount of heat accumulated in the subgrade structure before freezing process and also snow cover on the surface of track ballast applied before the period of thaw as a thermo-insulation layer.

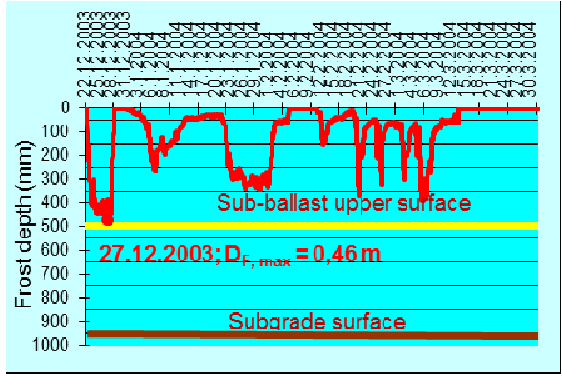

Figure 10: Frost depth value SS for winter 2003/2004.

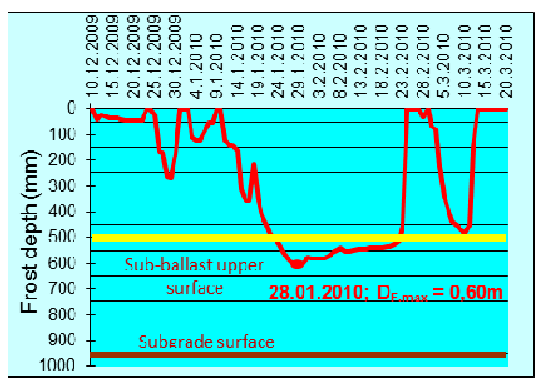

Figure 12: Frost depth value SS for winter 2009/2010.

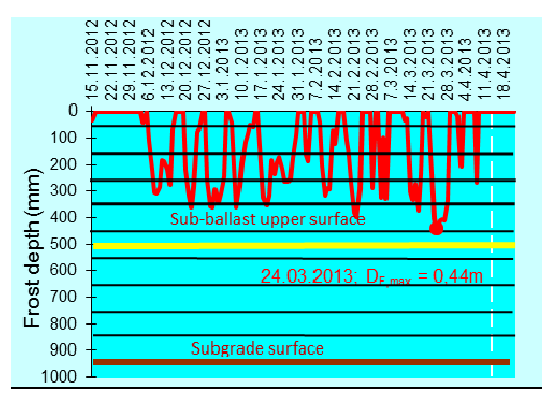

Figure 11: Frost depth value SS for winter 2012/2013.

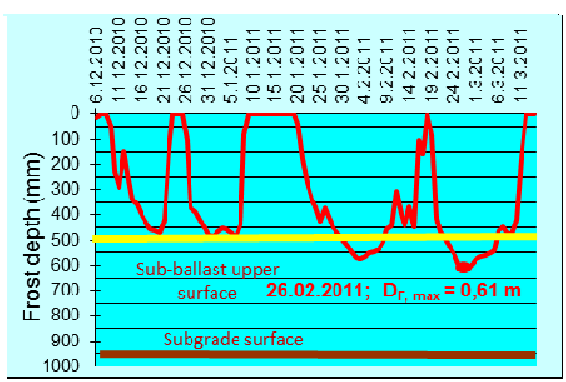

Figure 13: Frost depth value SS for winter 2010/2011.

\section{Design of nomogram for determining the structural thickness of the protective layer}

Based on the results of monitoring of climatic factor impacts on the temperature regime of the construction of subgrade structure of frost obtained so far under the experimental measurements since 2003 on Experimental Stand DRETM I and the necessity of amendment of design methodology of subgrade structure design (hereinafter referred to as "SS") to the adverse effects of frost specified in [1], there is described a proposal draft of design nomogram in the next part of this contribution, which partly reflects the facts already mentioned in the conclusion of Chapter 3. Simultaneously valid design nomogram given in [1] is based on the draft thickness of the protective layer just under the frost index for the area where the railway track is upgraded or will be implemented as a new building. Since the experimental measurements showed that the maximum frost value 
reached in subgrade structure does not only affect the frost index reached for the winter period, but also the average annual temperature, thus the amount of heat accumulated in the construction of subgrade structure before freezing process, it is also necessary to incorporate the impact of mean annual temperature $\theta_{m}$ to change of temperature regime of subgrade structure $T_{s s}$ into the design methodology.

Using experimentally measured temperatures in the construction of SS of Experimental Stand DRETM I there were set relations describing warming of subgrade structure during the summer period, resulting from a comparison of the heat index $I_{h, 1}$ with the increase of heat in the level of subgrade and railway substructure body. Then, the impact of mean annual temperature $\theta_{m}$ (amount of heat accumulated in the SS construction) to design of the thickness of protective layer is then taken into account in determining "consumption" of frost index to penetration of zero isotherm to the level of the subgrade depending on the initial temperature of the SS construction. There are shown the values of frost indices considered in table 2 , which are necessary to fully freezing of the subgrade body of railway substructure, or subgrade.

Table 2: Index values causing complete freezing of the SS construction up to the level of subgrade, or railway substructure body with respect to $T_{m}$.

\begin{tabular}{|c|c|c|}
\hline Mean annual temperature & \multicolumn{2}{|c|}{ Frost index $\boldsymbol{I}_{\boldsymbol{F}}\left({ }^{\circ} \mathrm{C}\right.$. day $)$} \\
\cline { 2 - 3 } & $\begin{array}{c}\text { Sub-ballast } \\
\text { upper surface }\end{array}$ & Subgrade surface \\
\hline 5 & 25 & 324 \\
\hline 6 & 32 & 331 \\
\hline 7 & 48 & 347 \\
\hline 8 & 85 & 384 \\
\hline 9 & 111 & 409 \\
\hline 10 & 183 & 482 \\
\hline
\end{tabular}

The values listed in table 2 were used to construct the design nomogram to determine the thickness of the protective layer in the process of the design of the SS construction to the adverse effects of frost - fig. 14 .

\section{Conclusion}

Experimental monitoring of temperature regime of subgrade structure, implemented on Experimental Stand DRETM I, demonstrated the validity of its construction not only because the climatologists speak over a long time about global warming of the Earth and thus reducing the average daily temperatures in winter and increasing daily temperatures in summer, which would be result for the achievement of smaller frost depths of the constructions of linear traffic engineering structures in the future. Based on the present information from long- 


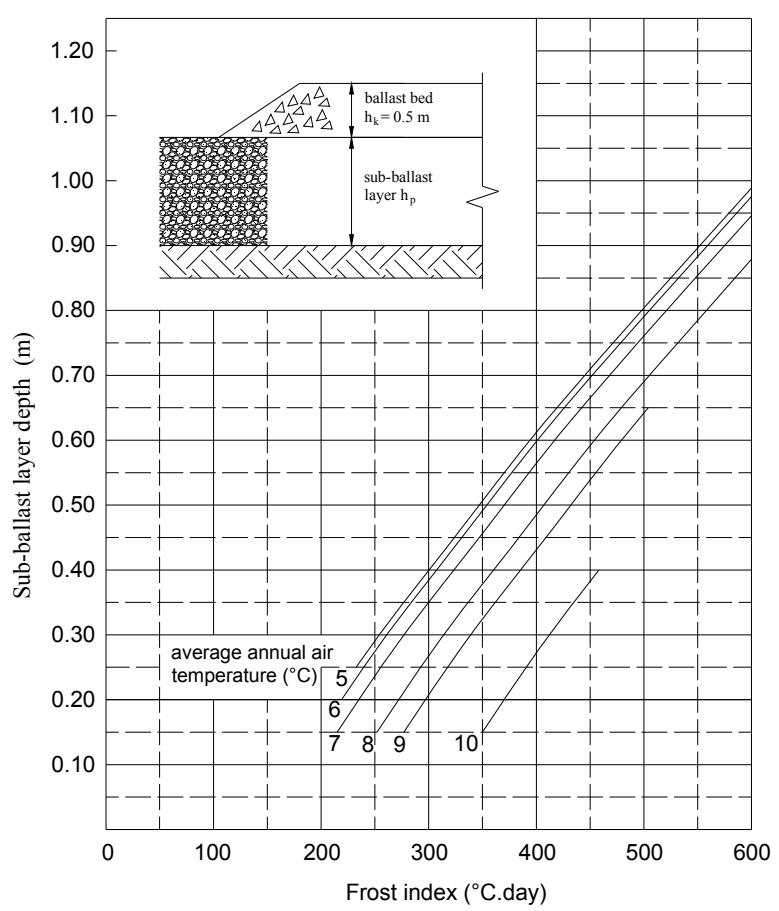

Figure 14: Design nomogram for determining the thickness of protective layer.

term experimental measurements of the temperature regime of the model of the railway track (Experimental Stand DRETM I) obtained so far, it can be stated that the design of structural thickness of its protective layer should not be based only on the known value of the frost index for the area that railway passes through, but it is necessary to take into account the course of summer period (amount of heat accumulated in the subgrade structure), course of winter period (number of periods of frost and thaw, duration, presence of snow cover), granulometric composition, volumetric weight, degree of pollution (mainly track ballast) and humidity of each construction layers of subgrade structure and probably the shape of ground body (embankments, side-hill cut, cut). The current research has also confirmed the fact that the relation to calculate frost depth depending on the frost index is not objective and it has not been achieved over 10 year monitoring of temperature regime of present construction, despite the fact that the zero isotherm reached the level of subgrade.

\section{Acknowledgements}

The contribution is the partial output of the grant project VEGA 1/0756/12 "Experimental monitoring and mathematical modelling of temperature regime of subgrade structure" and it was published with the financial support of the project 
"Support of quality of education and research for area of transport as an engine of economics", (ITMS: 26110230076), which is co-financed from sources of the European Social Fund.

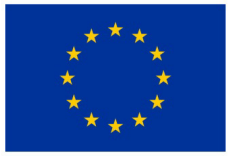

Európska únia

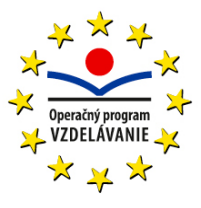

Agentúra Ministerstva školstva, vedy, výskumu a športu SR pre štrukturálne fondy EÚ

\section{References}

[1] TNŽ 73 6312, Design of construction layers of subgrade, Standard of Slovak Railway, GR ŽSR, 2005.

[2] Ižvolt L., Railway substructure - stress, diagnostics, design and implementation of body construction layers of railway subgrade, Scientific monograph, EDIS Žilina, 2008, 324 p., ISBN 978-80-8070-802-3.

[3] Kupčuliak, P., Design and assessment of the railway subgrade construction from the aspect of climatic factors load, Dissertation thesis, University of Žilina, Faculty of Civil Engineering, DRETM, p. 142, 2011.

[4] Decký, M., Remišová, E. \& Juhás, M., Impact of Climatic Characteristics on Dimensioning of Road Construction in Tunnels in Slovakia. $13^{\text {th }}$ International Multidisciplinary Scientific Geoconference SGEM 2013, Energy and Clean Technologies - Conference Proceedings, 16-22 June 2013, Albena, Bulgaria, ISBN 978-619-7105-03-2, ISSN 13147-2704, DOI: $10.5593 /$ sgem 2013. 